\title{
Melanoma in the elderly patient: a single institution retrospective analysis
}

\author{
Vincenzo Desiato*, Gennaro Quarto, Stefano Perrotta, Gian Luca Benassai, Bruno Amato, Giacomo Benassai \\ From 26th National Congress of the Italian Society of Geriatric Surgery \\ Naples, Italy. 19-22 June 2013
}

\section{Background}

Debate around the reliability of age as a prognostic factor in melanoma patient has been intense. Age is likely a prognosis affecting factor in melanoma, either directly or indirectly, as it causes differences in diagnosis, biologic behavior and therapy. Furthermore there is lack of data from widest randomized controlled trials, because of the exclusions criteria for the elderly. Therefore the management of elderly patients with melanoma remains challenging. We undertook this study to identify factors associated with outcome.

\section{Methods}

A retrospective analysis was carried out on elderly (age $\geq 65$ ) melanoma patients treated in our institution from January 1995 to January 2008. We identified and analyzed 77 patients. A minimum of 60 months follow-up was available on all surviving patients. Mean follow up was $50.86 \pm 35.7$ months. A detailed retrospective analysis was conducted to identify prognostic factors for Disease Free Survival (DFS) and for Overall Survival (OS).

\section{Results}

The mean age was $76.26 \pm 7.07$ years. Forty-two patients (55\%) were male. Primary lesion sites were on lower limb (41.6\%), trunck (35\%), upper limb (14.3\%), head or neck (9.1\%). Mean Breslow thickness was $7.8 \pm 12.92 \mathrm{~mm}$. Mitotic rate (mitoses $/ \mathrm{mm}^{2}$ ) was divided into four groups: $<1$ mitosis $14.3 \%, 1 \leq$ mitoses < $335 \%, 3 \leq$ mitoses < 5 $19.5 \%, \geq 5$ mitoses $31.2 \%$. Ulceration was present in $54.5 \%$ of cases. There was a prevalence of nodular melanoma (52\%), followed by superficial spreading (35\%), lentigo maligna $(9.1 \%)$ and acral lentiginous $(3.9 \%)$. All

\footnotetext{
* Correspondence: vincenzodesiato@gmail.com University Department of General Surgery, Geriatric, Oncologic and Advanced Technologies, Faculty of Medicine and Surgery, Federico II University Hospital, Via S. Pansini 5, 80131, Napoli, Italy
}

patients were adequately treated considering margins and lymphatic basins management. Almost all underwent sentinel lymph node biopsy (SLNB), except two cases of thin melanoma ( 0.5 and $0.7 \mathrm{~mm}$ of thickness). We observed positive SLNB in 16/75 cases (21.3\%) with following completion lymph node dissection (CLND) that classified as N1 7 patients, as N2 6 patients and as N3 3 patients. Three patients (3.9\%) underwent total lymph node dissection (TLND) for clinically positive lymph nodes. Kaplan-Meier analyses were performed to determine the overall survival, 5-year DFS and 5-year OS for different risk factors. All statistical analyses used SPSS version 19 . With $\alpha$-criterion fixed at 0.05 we observed, in our cohort, that lymph node status, primary tumor thickness, mitotic rate and gender are very important prognostic factors in the elderly patient with melanoma.

\section{Conclusions}

As for the younger patient, aforementioned prognostic factors affect the prognosis in the elderly. Age, for its part, may worsen prognosis, increasing recurrence rates and negatively affecting DFS and OS. That being said, we should treat elderly patients as the younger and, since often the general conditions of aged patient preclude more aggressive medical therapies, surgery remains the most important therapeutic tool. Furthermore, as we know, the great challenge of our day is the early diagnosis.

\section{Published: 16 September 2013}

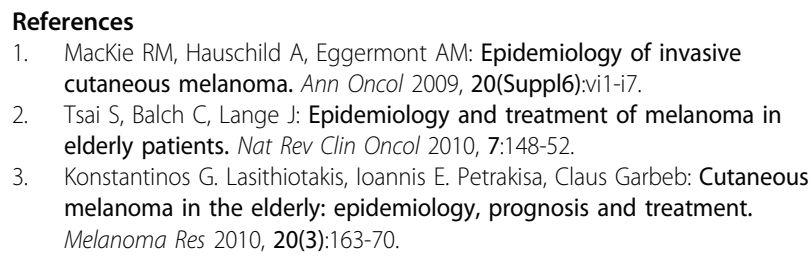
melanoma in the elderly: epidemiology, prognosis and treatment. Melanoma Res 2010, 20(3):163-70. 
4. Coups EJ, Geller AC, Weinstock MA, Heckman CJ, Manne SL: Prevalence and correlates of skin cancer screening among middle-aged and older white adults in the United States. Am J Med 2010, 123:439-45.

doi:10.1186/1471-2482-13-S1-A16

Cite this article as: Desiato et al:: Melanoma in the elderly patient: a single institution retrospective analysis. BMC Surgery 2013 13(Suppl 1): A16.

Submit your next manuscript to BioMed Central and take full advantage of:

- Convenient online submission

- Thorough peer review

- No space constraints or color figure charges

- Immediate publication on acceptance

- Inclusion in PubMed, CAS, Scopus and Google Scholar

- Research which is freely available for redistribution

Submit your manuscript at www.biomedcentral.com/submit 